\title{
LA GRAN FIGURA SILENCIADA: LA MUJER EN EL PRIMER SIGLO DE LA CONQUISTA RIOPLATENSE
}

\author{
MAR LANGA PIZARRO
}

Acontece a menudo que, una vez creída, la mentira viene a ocupar el lugar de la verdad.

Francisco López de Gómara

(1511-1566?)

Los primeros europeos que llegaron al Río de la Plata (1516) acompañaban a Juan Díaz de Solís en su búsqueda de un paso hacia las Indias Orientales. Un siglo más tarde (1617), durante el mandato del primer gobernador criollo, «La Provincia Gigante de las Indias» se dividió en dos gobernaciones ${ }^{1}$. Entre esas dos fechas, destacan otras importantes, como las fundaciones de Buenos Aires (1536 y 1580) y Asunción (1537), que fue repetidamente comparada con un «Paraíso de Mahoma» en el que reinaban la poligamia y los excesos sexuales.

Aunque resulte difícil imaginar un harén sin mujeres, estas no tienen suficiente entidad ni en los documentos coloniales ni en la literatura de la etapa independiente. Ante tal paradoja, nos propusimos estudiar la situación de las féminas rioplatenses durante la primera centuria de presencia española. En un intento de sintetizar lo encontrado en los textos, hemos estructurado este artículo en cuatro apartados: las españolas, las indígenas, las mestizas, y las negras y mulatas.

\section{LAS ESPAÑOLAS}

Según una opinión bastante asentada, la conquista fue llevada a cabo por hombres heroicos, casi legendarios. Así los describía Abel Posse en el artículo «Furia y grandeza ibéricas»:

Avanzaban por territorios imposibles. (...). Ganaron mucho menos que lo que dejaron, la salud, generalmente la vida. (...). Iban acosados por caries, reumas marítimos, melancolías de amor lejano, hongos, mosquitos, flechazos mal cicatrizados, rencores de sentina. (...) Seres estrictamente nietzscheanos, todo lo que no los mataba los hacía más fuertes. No se detenían a pensar que cada día era una hazaña y casi seguramente el último (...). Nadie puede vengarse del pasado, afirmaba Heidegger. Debemos comprender la historia en la dialéctica de los horrores y las nobles hazañas ${ }^{2}$.

Los únicos conquistadores a los que Posse se refiere son varones. Reproduce así la idea que ya enunciara Félix de Azara a principios del siglo XIX, cuando sostuvo: «los conquistadores llevaron pocas o ninguna mujer» ${ }^{3}$. Sin embargo, esto no es cierto: parece que había mujeres ya en la primera expedición de Colón ${ }^{4}$; está certificada la presencia femenina en el segundo viaje colombino (1493-96) $)^{5}$ y los

1

La llamada «Provincia Gigante de las Indias» abarcaba desde la línea del Ecuador hasta tierra de Fuego. En 1560 se segregó la Gobernación de Santa Cruz, y en 1569 se excluyeron de la demarcación la Hoya Amazónica y Región Cuyana. En la división de 1617, llevada a cabo bajo el cuarto mandato de Hernandarias (Asunción, 1564-1634) Buenos Aires se convirtió en la capital de la Gobernación del Río de la Plata, que comprendía las ciudades de Corrientes,
Santa Fe y Concepción del Bermejo, más sus respectivas demarcaciones.$$
2
$$

La Nación, 15-10-1990.

3

Félix de Azara, Descripción e historia del Paraguay y del Río de la Plata, Madrid, Impr. de Sanchiz, 1847. Disponible en la Biblioteca Virtual Miguel de Cervantes (en adelante, BVMC), http://www.cervantesvirtual.com/FichaObra. $\mathrm{html}$ ? Ref $=7080$. Así lo sostiene Juan Gil, «El rol del tercer viaje colombino", Historiografía y Bibliografía Americanistas, 30 (1985), pp. 83-110.

El propio Cristóbal Colón, en la Carta de Relación del segundo viaje, dice que entregó un niño indígena "a una muger que de Castilla acá benía» (Antonio Rumeu de Armas, Manuscrito del Libro Copiador de Colón, Madrid, ed. del autor, 1989, p. 450. Tomamos la cita de la tesis de María Montserrat León Guerrero, El segundo viaje colombino, Universidad de Valladolid, 2000). En los apéndices de esta tesis doctoral, se transcribe el documento que contiene los nombres de las personas que sirvieron a los Reyes Católicos en las Indias y tenían pendientes pagos por ese motivo (se halla en el archivo General de Simancas, Sección Contaduría Mayor de Cuentas, Primera Época, Legajo 98; y está datado en Ávila el tres de noviembre de 1497). Aparecen allí trescientos de los más de seiscientos pasajeros que participaron en el segundo viaje colombino y, entre ellos, figuran mujeres como María de Granada y las comerciantes Catalina Vázquez y Catalina Rodríguez.

La gran figura silenciada: La mujer en el primer siglo de la conquista rioplatense

MAR LANGA PIZARRO 


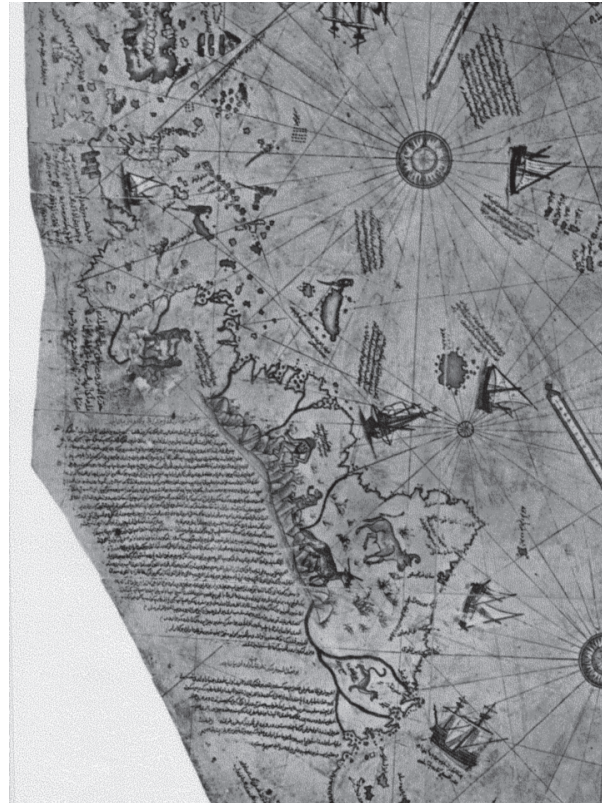

Mapa de Piri Reis (1513). Detalle: Sudamérica.
Reyes Católicos autorizaron al almirante a llevar trescientos hombres y treinta mujeres en su siguiente travesía (1497$98)^{6}$.

Por otra parte, atendiendo a la norma de Montalvo (1484), que establecía la obligación de la convivencia matrimonial, la Corona siempre insistió en que los conquistadores fueran con sus esposas al Nuevo Mundo: diversas órdenes del siglo XVI forzaban a los casados a la reagrupación familiar en América; y la Recopilación de Leyes de Indias de 1680 dedicó todo el título tercero del libro séptimo a «los casados y desposados en España e Indias que están ausentes de sus mujeres 6 Real Cédula de 23 de abril de 1497. Amadeo Julián (Bancos, ingenios y esclavos en la época colonial, Santo Domingo, Editora del Hogar, 1997, p. 65) da el nombre de cuatro de estas féminas: Catalina de Sevilla (mujer de Pedro de Salamanca), Gracia de Segovia (prostituta) y Catalina y María de Egipto (dos gitanas acusadas de homicidio).

7

Teresa Piossek Prebischa, "Las conquistadoras», Revista de la Fundación Cultural de Santiago del Estero. Disponible en http:// www.fundacioncultural.org/revista/nota9_17.html

8

Ulrich Schmídel (también conocido como Ulrico Schmidl), Viaje al Río de la Plata, Buenos Aires, Cabaut y Cía, 1903. Disponible en la BVMC, http://www.cervantesvirtual.com/FichaObra. $\mathrm{htm} \mid$ Ref $=4911$.

9

Ruy Díaz de Guzmán, Historia argentina del descubrimiento, población y conquista de las provincias del Río de la Plata, libro I, capítulos 1 y 2 . La obra fue publicada en 1835, pero la dedicatoria es de 1612, y se considera que la redacción comenzó en 1598. Hay edición a cargo de Enrique de Gandía (Madrid, Historia 16, 1986), y

La gran figura silenciada: La mujer en el primer siglo de la conquista rioplatense

MAR LANGA PIZARRO y esposas», con orden para que las autoridades los devolvieran a sus lugares de origen si no acataban la ley.

Según los registros de la Casa de Contratación de las Indias, de los 54.882 viajeros que llegaron a América en el siglo XVI, más del $18 \%(10.110)$ fueron mujeres. Se calcula, sin embargo, que la cifra total de españoles debió de ser cuatro veces superior a la registrada: entre 250.000 y 280.000 personas 7 . Esta diferencia se debe a que los datos están incompletos, y a la inmigración clandestina. En el caso femenino, la omisión en las listas de pasajeros resulta habitual ya que, al no ser contratadas a sueldo, no figuraban en los registros de cuentas. Además, el número de mujeres que viajaron sin papeles tuvo que ser porcentualmente mayor que en el de varones, porque religiosas y solteras requerían permiso expreso del rey, y algunos colectivos -extranjeras, «mujeres licenciosas», descendientes de procesados por la Inquisición, etc.- tenían prohibido el paso a América. Existen testimonios directos de lo sencillo que resultaba embarcarse clandestina-

\footnotetext{
el texto se halla digitalizado en la BVMC, http://www.cervantesvirtual.com/FichaObra. $\mathrm{html}$ ?Ref=6185. También recogen la historia de Lucía Nicolás del Techo (Historia de la Provincia del Paraguay de la compañía de Jesús, Asunción, A. de Uribe, 1897, libro I, capítulo IV; escrita en 1673) y Félix de Azara lop. cit., capítulo XX;
}

mente: por ejemplo, uno de los integrantes de la armada de Pedro de Mendoza (1536) relata cómo un pariente del adelantado introdujo en el barco a su amante y a la criada de esta ${ }^{8}$. Y el hecho de que Antonio de Guevara, en su tratado El Arte de Marear (1539), advierta de que las mujeres no pueden ir escondidas en galeras, supone una confirmación de que tal circunstancia era común.

\subsection{La expedición de Caboto (1526): Lucía Miranda, la Cautiva}

Sebastián Caboto partió de Cádiz en pos de las noticias sobre el «Mar Dulce» ofrecidas por los supervivientes de la expedición de Solís (1516). En 1527, Caboto fundó el fuerte de Sancti Spiritu, a unos cincuenta kilómetros de la actual Rosario, y se marchó a explorar el Paraná. Dos años después, el fuerte fue destruido por los indígenas. Según Ruy Díaz de Guzmán’, el cacique Mangoré se vengó así de los desdenes de la mujer de la que se había enamorado: la española Lucía Miranda, esposa del soldado Sebastián de Hurtado, ambos naturales de Écija. Como Mangoré no la consiguió con sus regalos, convenció a su hermano, el cacique Siripo, para atacar el fuerte, aprovechando la amistad con los españoles y la ausencia de muchos de ellos, que habían salido a buscar alimentos. Cuatro mil indígenas, previamente escondidos, quemaron Sancti Spiritu y mataron a sus moradores, excepto a las mujeres y los niños. Mangoré murió en el combate, y Siripo se llevó a Lucía como esclava. Más tarde, la hizo su esposa. Cuando Sebastián encontró el fuerte destruido, salió en busca de Lucía. Fue hecho prisionero, y condenado a muerte por Siripo, quien se apiadó de las súplicas de Lucía, y conmutó la pena por la imposibilidad de que los esposos españoles se vieran o hablaran. $\mathrm{Al}$ descubrirse que habían roto el acuerdo, Sebastián fue asaeteado hasta la muerte, y Lucía quemada viva.

Escritores de todas las latitudes han recreado esta historia. En el ámbito anglosajón, el poeta irlandés Thomas Moore es autor de la tragedia Mangora, King of Timbusians (Londres, Harvey, 1718), donde describió a los timbús como un pueblo sumamente rico de hombres negros y feos; y Charles Kingsley desarrolló la trama en el capítulo XII de Westward Ho! (Londres, Spencer Press, 1855), con planteamientos muy cercanos al romanticismo y a la novela sentimental. Ya en el Río de la Plata, Manuel José de Lavardén 
estrenó en el teatro bonaerense de la Ranchería la primera obra escrita por un autor nacido en el actual territorio argentino: la tragedia neoclásica Siripo (1789), que había dado a conocer el jesuita valenciano Manuel Lassala en Bolonia (1784).

Hacia $1860^{10}$, aparecieron dos novelas homónimas de las argentinas Rosa Guerra y Eduarda Mansilla: Lucía Miranda. Remedios Mataix $^{11}$ ha destacado el hecho de que dos mujeres se interesaran casi simultáneamente por la misma historia, en los años en que, tras la caída de Juan Manuel de Rosas (1842-1852), Argentina necesitaba para su construcción de nuevos mitos nacionales. Además, hay que considerar que la muerte de los esposos como mártires de su fe resultaba atractiva cuando triunfaba el ideal "progresista» de crear una Argentina blanca y urbana, en la que los indígenas habían de ser "civilizados» o exterminados.

En la dedicatoria de la edición de 1860, Rosa Guerra reconoce haber escrito su novela en quince días, y menciona otra obra con el mismo título. Seguramente se refiere a la que Eduarda Mansilla publicó en el diario La Tribuna, entre mayo y julio de ese mismo año ${ }^{12}$. Mucho más larga y menos sentimental que la de Guerra, la novela de Mansilla comienza cuando Caboto decide volver a España, y advierte a Nuño de Lara de los peligros de que Lucía se quede en tierras americanas. Inmediatamente retrocede hasta el momento en el que nace la protagonista, hija ilegítima de un noble y una morisca que muere durante el parto. Así, los treinta y cuatro capítulos de la primera parte transcurren en Europa; y, solo en la segunda parte (de veintiún capítulos), Lucía y Sebastián, ya casados, emprenden camino hacia América.

El paisaje de Guerra, como el de cualquier romántico, se adapta al ánimo de los protagonistas: mientras reina la paz, reproduce todos los tópicos del locus amoenus, «un verdadero edén»; sin embargo, cuando se aproxima el ataque al fuerte, «se preparaba una horrible tempestad». Por su parte, Mansilla elige el escenario de la pampa, que tanto juego dará en la literatura argentina.

Las novelas de Guerra y Mansilla tienen en común el hecho de poner en tela de juicio la violencia de los españoles. Guerra se refiere así a la conquista: «si la causa de la humanidad hubiera entrado directamente en el proyecto de estas empresas hubieran sido menos desgraciadas»; Mansilla va más allá, y denuncia los abusos que sufren los «desgraciados habi- tantes del Nuevo Mundo». Además, las dos destilan influencias cristianas, quizá heredadas de Chateaubriand. Con Guerra, el tema religoso llega a su máxima expresión en los momentos más terribles del relato: Magorá, creyendo a Lucía muerta, le ofrece al dios cristiano abrazar su fe si la salva; ya moribundo solicita a Lucía que lo bautice; y los esposos españoles mueren «arrodillados (...) por más de media hora se les pudo ver a travez [sic] de las llamas en tan religiosa actitud». Distinto es el planteamiento en Mansilla: Lucía vence al brujo Gachemañé, y trata de convertir a los indígenas al cristianismo, pero permite que Anté se prepare para el matrimonio según los ritos de su pueblo. Las costumbres nativas, que apenas aparecen en la novela de Guerra, constituyen un núcleo importante dentro de la segunda parte de la obra de Mansilla. Y ambas reúnen lo peor del tópico sobre el salvaje en la figura de Siripo, como si los dos hermanos constituyeran las caras de una misma moneda: la visión romántica del «indio», heredera del buen salvaje de Rousseau, perfila la figura de Mangoré.

Como las mujeres de sus artículos (para las que reivindicó la igualdad y la educación, sin dejar de exigirles que fueran madres piadosas y ejemplares), la Lucía de Guerra resulta un personaje interesante y ambiguo: es modelo de esposa, pero no por ello renuncia a la actividad pública, consistente en educar al indígena, evangelizarlo, «conquistarlo». Por su parte, la Lucía de Mansilla, febril lectora desde los trece años, se describe como astuta, hermosa e inteligente: pronto aprende la lengua de los timbús, y en ella recae la responsabilidad de instruir a los nativos (sobre todo, a las nativas, a quienes trata de transmitir los valores vigentes en la Argentina de la época de la autora: buenas costumbres, higiene, adecuado cuidado de los hijos...).

Lucía siguió teniendo presencia en la literatura posterior. Miguel Ortega publicó Lucía Miranda. Drama en cinco actos y en verso (Buenos Aires, Porvenir, 1864); Celestina Funes dio a la imprenta el largo poema Lucía Miranda, episodio nacional (Rosario, El Mensajero, 1883); y Alejandro Rómulo Cáneja se ocupó de ella en Lucía Miranda o la conquista trágica (Buenos Aires, Maucci, 1907). En torno a 1928, apareció en París la novela Lucía Miranda, de Gustavo Martínez Zuviría (Hugo Wast), uno de los escritores más populares de la Argentina de su momento, y uno de los difusores del ideario nacionalista católico y reaccionario, que pretendía explicar

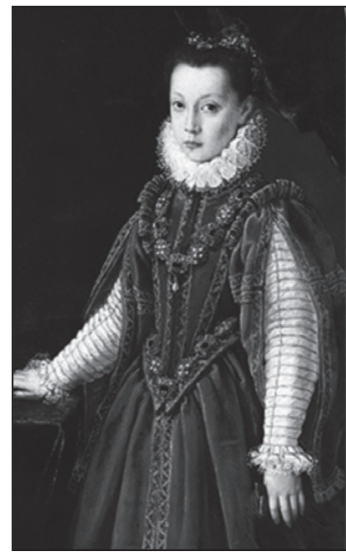

Sofonisba Anguisola, Retrato de una joven dama (ca 1573).

10

Es la fecha de publicación que suele darse para novela de Rosa Guerra, y coincide con la edición de la Imprenta Americana de Buenos Aires (digitalizada en la BVMC, http://www.cervantesvirtual.com/FichaObra $\mathrm{htm}$ ? Ref=3157). Sin embargo, la edición de la Biblioteca Digital Argentina dice basarse en una anterior: Buenos Aires, Facultad de Filosofía y Letras, Instituto de Literatura Argentina, 1956.

11

Remedios Mataix, «La escritura (casi) invisible. Narradoras hispanoamericanas del siglo XIX», Anales de Literatura Española (Universidad de Alicante), 16 (2003). pp. 46-47. La misma autora trata también el tema en «Romanticismo, feminidad e imaginarios nacionales», Río de la Plata, 29-30 (2006), pp. 209-224.

12

Apareció bajo el pseudónimo de Daniel y tuvo traducción al inglés. Así lo explicó la propia Mansilla cuado recogió Lucía Miranda en un libro publicado en Buenos Aires, Imprenta Alsina, 1882 (en la BVMC, http:// www.cervantesvirtual.com/FichaObra.html?Ref=3341)

La gran figura silenciada: La mujer en el primer siglo de la conquista rioplatense

MAR LANGA PIZARRO 


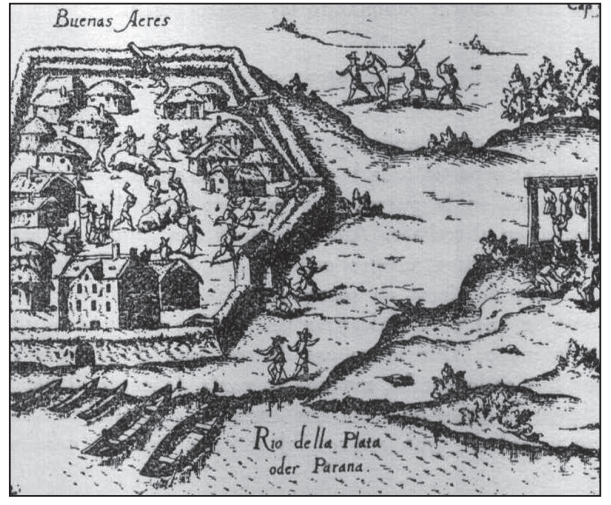

Buenos Aires. Ilustración de Levino Hulsino. Edición Princeps de la obra de Schmidl.

13

Eduardo Madero, Historia del puerto de Buenos Aires, Buenos Aires, Compañía Imprenta Argentina, 1955 ( $1^{\underline{a}}$ ed.: 1892).

14

Del Techo, dejando traslucir su condición de religioso, insiste mucho en este tema: Mangoré, "el bárbaro», "se abrasó en las llamas de amor ilícito», "sin otro fin que el de gozar una mujer», Lucía guardaba «todo recato», y Sebastián valoraba "antes que todo el honor de su esposa». Cuando apresó a Sebastián, Siripo ardía "en celos», y puso como condición que Lucía "no viviera matrimonialmente con su esposo». Al encontrarlos «mientras se daban al amor conyugal», ordenó su muerte: "Lucía, (...) rogaba á Dios que (...) la llevase á la patria eterna; haciendo tales votos, murió abrasada. Sebastián Hurtado fué atado á un árbol, y como si representara al santo de su nombre, fué atravesado por las flechas de los indios mientras oraba piadosamente».

\section{5}

La carta de Isabel de Guevara a la Princesa Gobernadora Doña Juana se halla en el Museo Histórico de Madrid, y ha sido recogida por Marcos Jiménez de la Espada (Cartas de Indias, Madrid, Imprenta de Manue G. Hernández, 1877), Josefina Cruz (comp., Cronistas de Indias. Los Fundadores, Buenos Aires, Ministerio de Cultura y Educación, 1970, p. 27) y Gladys Lopreto (ed, ... Que vivo en esta conquista, La Plata, Edulp, 1996, cap. 3). Está digitalizada en los apéndices del texto de Schmidl en la BVMC (op. cit.).

La gran figura silenciada: La mujer en el primer siglo de la conquista rioplatense

MAR LANGA PIZARRO bigamia $^{14}$.

la crisis argentina apelando a la presencia de inmigrantes. Era lógico que a Wast le interesara la historia de Lucía, donde los indígenas son los malvados ejecutores de unos conquistadores cristianos a los que el autor admira. Pero Lucía sedujo también a otros autores: Felipe Boero y Luis Bayón Herrera elaboraron la ópera Siripo (1924, revisada en 1937); y la paraguaya Concepción Leyes hizo su particular interpretación en Río lunado, mitos y costumbres del Paraguay (Buenos Aires, Peuser, 1951).

Mucho se ha discutido sobre la existencia de Lucía Miranda, que se dio por cierta hasta que la cuestionó Eduardo Madero' ${ }^{13}$. Si la historia de Lucía fuese real, supondría, desde los primeros momentos de la conquista del Río de la Plata, la presencia de españolas: cinco o seis según Díaz de Guzmán y Nicolás del Techo, al menos una según Azara. Si fuese una leyenda, su incursión en el relato de Díaz de Guzmán se explicaría como un intento de exaltar la monogamia frente a la actitud de los españoles afincados en la zona, después de que el Concilio de Trento (1542-63) hubiera subrayado la importancia de la fidelidad, y de que los monarcas Carlos V (1500-1558) y Felipe II (1527-1598) hubieran reprobado la

\subsection{La armada de Mendoza (1535): Isabel de Guevara y la Maldonada}

El hecho de que no exista documentación sobre Lucía Miranda no significa que su historia sea una invención: tampoco figura Isabel de Guevara, autora de una valiosa carta dirigida a Juana La Loca, en la que da cuenta de las vicisitudes por las que pasaron los fundadores de Buenos Aires ${ }^{15}$.

16

Según Centenera (La Argentina, Buenos Aires, Jacobo Peuser, 1912; en la BVMC, http:// www.cervantesvirtual.com/ FichaObra.html? Ref=6789), Pedro de Mendoza padecía sífilis ("el morbo que de Galia tiene nombre»), lo cual concuerda con los síntomas que manifestaba.

\section{7}

Agustín Zapata Gollán, «Mujeres de España en el Río
A pesar del silencio de sus compañeros de expedición y de los cronistas posteriores, es evidente que esta mujer y algunas otras viajaron en la armada de Pedro de Mendoza (1535), la mayor enviada hacia América hasta aquel momento. Entre sus integrantes, estaban el bávaro Ulrico Schmidl, autor del ya citado Viaje al Río de la Plata; y el clérigo-soldado Luis de Miranda, primer poeta del Río de la Plata, que escribió en Asunción, hacia 1545, su crónica en versos de pie quebrado. Ninguno de ellos menciona que con Mendoza viajaran mujeres, aunque sí dan cifras de los hombres y los animales. Por la carta de Isabel de Guevara (1556), sabemos que ella no era la única fémina: "avemos venido çiertas mugeres, (...) con mill é quinientos hombres».

Durante el viaje, la enfermedad del adelantado ${ }^{16}$ lo obligó a delegar en Juan de Osorio, a quien acabó mandando matar, acusándolo de traición. Sin justificar su tesis, Agustín Zapata argumenta:

este pequeño grupo de mujeres de la expedición, cantaba y bailaba para Osorio (...). No sería aventurado pensar que esta adhesión femenina motivo de celos [sic], (...) lo que movió la terrible y solapada máquina de intrigas que llevó a don Pedro de Mendoza, a dictar contra él cruel sentencia de muerte ${ }^{17}$.

Esta idea concuerda con el tópico de que las que se embarcaron hacia América eran prostitutas, y con la costumbre histórica de hacer a las mujeres culpables de las desdichas: desde la bíblica Eva, a la griega Helena, pasando por la Cava española o la Malinche mejicana.

Una vez fundado el fuerte de Buenos Aires, la armada quedó diezmada por el hambre y los ataques de los nativos. Guevara relata la aportación de las mujeres, que contrasta con el desmayo masculino:

Vinieron los hombres en tanta flaqueza, que todos los travajos cargavan de las pobres mugeres; ansi en lavarles las ropas, como en curarles, hazerles de comer (...), alimpiarlos, hazer sentinela, rondar los fuegos, armar las vallestas, (...) cometer á poner fuego en los versos, y á levantar los soldados, (...) dar arma por el campo á bozes, sargenteando y poniendo en orden los soldados.

Patricia Da Luz («Mujeres del olvido, heroínas de la historia», La Revista. Diario Primera Edición, 22 de julio de 2001) afirma que fueron una veintena. Teresa Piossek Prebischa (art. cit.) da los nombres de once.
De dar crédito a sus afirmaciones, hemos de suponer una importante presencia femenina en la expedición de Mendoza: las pocas mujeres de las que tenemos constancia ${ }^{18}$ no hubieran sido capaces de ocuparse de tan- 
tos asuntos, y de un contingente de entre quinientos y dos mil quinientos hombres. Guevara pone como aval de sus palabras a sus compañeros: «si no fuera por la honrra de los hombres, muchas mas cosas escriviera con verdad y los diera á hellos por testigos». Quizá una de las «cosas» que calla es el canibalismo, que queda probado porque Antón López de Aguiar recibió un indulto del rey, en el que perdonaba a los españoles por haber recurrido a la antropofagia ${ }^{19}$. Frente al silencio de Isabel de Guevara al respecto, los hombres dan cuenta de cómo el hambre llevó a los españoles a comer carne humana: lo relatan Luis de Miranda, Schmidl, Villalta y Díaz de Guzmán, entre otros.

Lo que queda de la expedición emprende un duro viaje hacia Asunción: según Schmidl, «de los 400 hombres, 50 sucumbieron»; según Villalta «murieron casi 100 hombres de pura hambre» ${ }^{20}$. De nuevo Guevara, y esto es uno de los rasgos «femeninos» de su escritura, se centra menos en las cifras que en la labor de las mujeres, marcada por una aceptación de los hechos, frente al desánimo pasivo de los varones. Como en el caso de Buenos Aires, son ellas las que aportan comida, cocinan e incluso gobiernan el barco.

Cuenta Guevara que también son las mujeres las que se ocupan de todo en las nuevas tierras: «fué nesesario que las mugeres boluiesen de nuevo á sus trabajos, haziendo rosas con sus propias manos, rosando y carpiendo y senbrando y recogendo el bastimento sin ayuda de nadie, hasta tanto que los soldados guareçieron de sus flaquezas». La autora se queja de que tantos esfuerzos no hayan tenido frutos («me dexaron de fuera, sin me dar yndio ni nengun genero de serviçio»), y pide como compensación un cargo para su marido: «estoy casada con (...) Pedro d'Esquiuel, (...) suplico mande me sea dado mi repartimiento perpétuo, y en gratificaçion de mis serviçios mande que sea proveydo mi marido de algun cargo, conforme á la calidad de su persona; pues él, de su parte, por sus serviçios lo merese». Puede avalar su testimonio el hecho de que Pedro de Esquivel figure en la documentación de la época, así como en las crónicas de Díaz de Guzmán y de Centenera.

De la misma manera que sus compañeros, los literatos anteriores al siglo XX olvidaron a Isabel de Guevara. Mujica Láinez le otorgó un papel secundario en «El primer poeta» (Misteriosa Buenos Aires, Buenos Aires, Sudamericana, 1951), donde la describía así: «Es la mejor. En tiempos del hambre y del asedio, dos años atrás, se portó como ninguna: lavaba la ropa, curaba a los hombres, rondaba los fuegos, armaba las ballestas. Una maravilla. Ahora es una enamorada más, y en ese arte, también la más cumplida». Como no sabemos de Isabel sino lo que ella nos dice en su carta, no resulta difícil imaginarla a la voluntad de los escritores. En un pasaje de la novela $D e$ lo dulce y lo turbio (Asunción, Centenario, 1997), Carlos Colombino insiste en el tema del canibalismo, precisamente uno de los que no refiere Isabel:

Esto es un trabajo para manos de hombres, aunque trocear un muslo humano es igual que trocear uno de cerdo (...) ¿Qué crees que hice ayer a la tarde? ¡Pues cocinando pedazos! Ahora quieren que los cortemos sin que sean reconocibles -apuntó Isabel y añadió-. Y no resulta fácil. Aunque a decir verdad, no hay mucha distancia entre carne de cerdo y carne de hombre.

Además, le dedica uno de sus Romances de la conquista (Asunción, Ingrapar, 2000) Hugo Rodríguez Alcalá; y, en 2004, se representaba en Buenos Aires un monólogo teatral sobre su figura, escrito por Alicia Muñiz y dirigido por María Esther Fernández.

Gracias a su carta, sabemos que Isabel de Guevara existió; «La Maldonada» tiene visos de leyenda, aunque aparezca en las crónicas. Según Díaz de Guzmán, «La Maldonada», desesperada por el hambre de Buenos Aires, decidió salir del recinto fortificado. Se refugió en una cueva, donde encontró una leona a la que ayudó a parir. Agradecida, está la alimentaba. Un día La Maldonada bajó a beber agua, fue capturada por los indígenas, y uno de ellos la hizo su esposa. Cuando los españoles la encontraron, Francisco Ruiz (o el capitán Alvarado, según las versiones) ordenó que la ataran a un árbol desnuda, para que sirviera de comida a las fieras y de escarmiento a sus compatriotas. Los soldados que acudieron a buscar sus restos la hallaron viva, porque la leona la había protegido. Decidieron entonces perdonarla, y darle su nombre al arroyo al lado del cual había sido atada.

No faltan leones en los relatos literarios de base histórica: recuérdese el episodio con el que comienza «La afrenta de Corpes», en El cantar de Mio Cid (hacia 1140). Además, resultan evidentes las conexiones entre la historia de La Maldonada y la de San Jerónimo, que sacó una espina de la pata de un león y así lo domesticó; o la del bíblico Daniel, a quien Dios salvó de los leones por confiar en él.
19 Herrera, Décadas. VI, libro III, cap. XVIII. Tomamos la cita de Samuel A. Lafone Quevedo, Prólogo a la obra citada de Schmidl.

20

Carta de 1556, conservada en la Biblioteca de la Real Academia de la Historia, Colección de Muñoz, tomo 80, folios 331 341 , 1536-56. Reproducida en los anexos de la obra de Schmidl de la BVMC (op. cit.).
La gran figura silenciada: La mujer en el primer siglo de la conquista rioplatense

MAR LANGA PIZARRO 
21

Puede que la atribución sea apócrifa, ya que Fedro (siglo I) no la incluyó en su versión latina de las fábulas de Esopo.

22

Existe una edición en italiano de las fábulas de Chabannes, en el tomo tercero de Favolisti latin medievali (F. Bertini y P. Gatti, Universidad de Génova, 1988); el relato de William Caxton, "Of the lyon \& of the pastour», aparece recogido por Robert Lenaghan, (Aesop's Fables, Cambridge, Harvard University Press, 1967); la carta de Antonio de Guevara a Antonio de la Cueva se publicó en el volumen Epístolas familiares (Madrid, Fundación José Antonio Castro, 2004, pp. 94-164; la historia de Androcles ocupa las páginas 158-163) disponible en la BVMC (http:// www.cervantesvirtual.com/FichaObra.htmle Ref=16896); también hay edición digital en la BVMC del texto de Montaigne, basada en Ensayos de Montaig ne seguidos de todas sus cartas conocidas hasta el día, París, Casa Editorial Garnier Hermanos, 1912, 2 vols. (http://www. cervantesvirtual.com/FichaObra.html?Ref=1844)

23

Los castigos eran durísimos durante la conquista: un miembro de la frustrada expedición de Jaime Rasquin al Río de la Plata da cuenta de la condena a muerte del contramaestre y de la mutilación sexual de dos grumetes porque los descubrieron manteniendo relaciones sexuales entre ellos.

24

Cabe recordar que la reputación femenina se basaba en valore como la castidad y la fidelidad, de las que dependía el honor de toda la familia. En 1588, las "Leyes de Estilo» corroboraron lo que ya era un hecho: la potestad del marido para asesinar a la esposa infiel.

La gran figura silenciada: La mujer en el primer siglo de la conquista rioplatense

MAR LANGA PIZARRO
Más paralelismos todavía existen con la fábula "Androcles y el león», atribuida a Esopo ${ }^{21}$ (siglo VII adC): el esclavo Androcles, huyendo de los malos tratos de su amo, se interna en la selva, y se refugia en una cueva, donde le extrae una espina de la pata a un león que, agradecido, se convierte en su abastecedor de comida, hasta que unos soldados encuentran al esclavo, y se lo devuelven a su amo. El castigo para tales casos consistía en luchar con un león hambriento. Casualmente, el que se enfrenta a Androcles es su viejo amigo: en lugar de devorarlo, le lame los pies. Ante tal maravilla, el esclavo y el león son liberados.

Puede que Díaz de Guzmán conociera este relato cuando redactó su obra, ya que se hallaba bastante difundido: lo había recogido Séneca (siglo I); lo narró Aulo Gellio (siglo II), quien dijo haberlo tomado de Apión (siglo I adC); y lo relató Ademar de Chabannes (siglo XI). En 1484, William Caxton tradujo al inglés un códice latino de Walter de Inglaterra que contenía la fábula «Of the lyon \& of the pastour»; en 1529, Antonio de Guevara situó la historia en los tiempos del emperador Tito, aclarando «cuenta esta hystoria Auliogelio latino, y muy más 'ad longum’ Apio el griego»; y años antes de que Díaz de Guzmán escribiera sobre La Maldonada, Montaigne (1533-1592) incluyó la historia del león y el esclavo en sus Ensayos ${ }^{22}$.

Quizá consciente de que el episodio podía sonar a recreación de una fábula, Díaz de Guzmán se esforzó en certificar la veracidad del caso: «yo la conocí, y la llamaban la Maldonada». En su edición de la obra, Enrique de Gandía defiende la veracidad de los hechos, basándose en que Francisco Ruiz Galán fue acusado por Antonio de Trinidad de castigar a los conquistadores atándolos a un árbol para que fueran devorados por las fieras. Además, Nicolás del Techo, en el capítulo VIII de su obra antes citada, comenta:

quién la juzgó [a La Maldonada] con tan grande severidad (...) es cosa que ignoro. Tengo averiguado que entonces las leyes eran inexorables; un soldado, porque robó una lechuga, quedó sin orejas; otro fue mutilado por quitar una berza; aún se conservaba entre los colonos la severidad de los juicios de Europa, la cual ojalá continuara ${ }^{23}$.

Probablemente la mezcla de la verdad con las leyendas, y la presencia de mujeres en la armada de Mendoza, expliquen el relato de La Maldonada que hace Díaz de Guzmán. En él se inspiró Maldonada, costumbres criollas
(Buenos Aires, Artística, 1898), del periodista español afincado en Argentina Francisco Grandmontagne; y, casi un siglo más tarde, la obra para títeres de igual título que se representaba en Madrid en 1981.

\subsection{Doña Mencia, la Adelantada, y su expe- dición de cincuenta mujeres (1550)}

En 1547, el adelantado Juan de Sanabria firmó una capitulación que incluía el compromiso de llevar a Asunción a ochenta doncellas y a un centenar de hombres casados con sus familias. Murió durante los preparativos, pero su viuda, Mencia de Calderón, decidió hacer de «Adelantada»: mientras se tramitaba que su hijastro Diego heredara el título, partió de San Lúcar (1550) con tres naves comandadas por el tesorero real Juan de Salazar. En la expedición viajaban más de cincuenta mujeres, entre las que se hallaban doña Mencia con sus tres hijas, su amiga Isabel de Contreras y las hijas de esta.

Cinco años duró la travesía, que la propia Mencia relató en 1564. Sufrieron tormentas, ataques de piratas, varios meses de retención en Brasil, y un último tramo de mil kilómetros a pie a través de la selva, que llevó al descubrimiento de los saltos del Guairá. Parece que en el viaje perecieron diez mujeres, incluida una de las hijas de doña Mencia. Por su parte, una de las de Isabel de Contreras, Elvira, contrajo matrimonio con el capitán Ruy Díaz Melgarejo, del que tuvo cuatro hijos y una hija. Su marido, sospechando una relación con su confesor y compañero de viaje, el padre Carrillo, los asesinó a los dos. Así lo relata Centenera (1602) en el canto sexto de La Argentina:

Amor, que con lo bajo lo alto iguala, la hace aficionarse a Juan Carrillo. (...) aunque la dama es tal, y el galán viejo, a entrambos los ha muerto Melgarejo. Entrando el Capitán en su aposento, al adúltero mató de una estocada ${ }^{24}$; la dama viene al grito con lamento, la gente viene al grito alborotada.

Ayúdanla a matar, oh crudo cuento, ¡que no hay quien te defienda, desdichada!

Aunque la llegada de un nutrido grupo de españolas debió de cambiar notablemente el panorama asunceño, y aunque su viaje resulte muy propicio como argumento de una novela de aventuras, su presencia en la literatura ha sido muy escasa. Recoge el tema uno de los Romances de la Conquista, de Hugo Rodrí- 
guez Alcalá; y hay diversas referencias a la expedición en la novela de Julio A. Sierra, $L a$ Nusta Ortiz (Buenos Aires, Sudamericana, 2000) cuyo narrador la llega a calificar de epopeya que excita las mentes de las muchachas. Al margen de eso, se conocen un par de novelas históricas: una reciente, de la española Eloísa Gómez-Lucena (Expedición al Paraíso, Sevilla, Espuela de Plata, 2004), y la de la argentina Josefina Cruz (Doña Mencia la Adelantada, Buenos Aires, ed. de la autora, 1960). En esta última, durante una conversación con la protagonista, Irala afirma:

Este libertinaje que justamente repudiáis trajo, sin embargo, cierta civilización al Paraguay: la fusión incontrolable de los sexos fue el mejor medio para ganar el entendimiento con los naturales (...) no nos fue dado elegir (...) los caciques, al sellar pactos y alianzas ofrecen sus hembras en prueba de amistad; ofensa hubiera sido rechazarlas (...) éramos un puñado de blancos perdidos (...) España nos dejó abandonados (...) traíamos la sangre alborotada de deseos, de soberbia, de hombría (...) el amor de las indias hizo posible la Conquista, pero (...) añorábamos la vida de hogar (...) el amor de nuestras mujeres (...) mucho antes, debisteis haber llegado (p. 235).

Esta visión de los hechos, que concuerda plenamente con la tradicionalmente difundi$\mathrm{da}$, tiene su importancia para comprender las relaciones entre los españoles y las indígenas.

\subsection{La armada de Zárate (1572): otras se- tenta mujeres}

El siguiente número importante de mujeres llegó a Asunción con el adelantado Juan Ortiz de Zárate, cuyo contrato con Felipe II fue el último que se firmó para la conquista del Río de la Plata: de las cuatrocientas personas que acompañaban al Adelantado, setenta eran mujeres. Martín Barco de Centenera, que viajaba en la expedición, dedica los cantos VIII y IX de La Argentina a relatar el dificultoso trayecto: la armada sufre la falta de pericia de los navegantes, varios temporales, ataques de los indígenas en Brasil... Sin embargo, el principal problema fue el hambre: «a muchos el pellejo como manto / les cubre aquellos huesos descarnados; / (...) Hoy mueren diez, mañana mueren veinte (...) / los niños descaecidos sollozando, / (...) y las madres maldicen su ventura». Según Centenera, esta situación hizo desertar a varios hombres, que fueron condenados a muerte. Así las cosas, comieron cuanto encontraron, y llegaron al canibalis-

mo: «Las tripas le sacara a un ahorcado, / y al medio del cocer se las comía. / Los huesos se roían de finados». Centenera no disimula su antipatía por las mujeres: aunque reconoce que «la gente alborotada sin consuelo / levantan alaridos hasta el cielo» y que «de temor lloran hombres y doncellas», ridiculiza el pavor femenino ante esas circunstancias. Incluso parece molestarle que, a pesar de «lo que en la isla padecieron / al fin todas con vida escabulleron» 25 .

No conocemos ninguna obra que se centre en lo acontecido con las mujeres que acompañaron a Zárate. La Ñusta Ortiz relata con detalle la preparación del viaje y las dificultades del mismo pero, aunque menciona a las féminas, apenas si se ocupa de ellas.

\section{LAS INDÍGENAS}

El mismo año de la fundación de Asunción (1537), la Bula «Subliminus Deus» reconocía a los indígenas como seres humanos; y un quinquenio más tarde se dictaron las Nuevas Leyes de Indias ${ }^{26}$, que prohibían la esclavitud y los trabajos forzados de los nativos ${ }^{27}$. Además, hubo numerosos llamamientos de la Corona a los conquistadores, instándolos a respetar los bienes y la libertad de los indígenas ${ }^{28}$. En el mismo sentido dictaron leyes Cabeza de Vaca, Hernandarias y otros gobernadores del Río de la Plata. A pesar de ello, en 1581, Felipe II admitía ante la audiencia de Guadalajara que un tercio de

25

Por si su misoginia no queda clara, la argumenta al final del canto IX: «Pregunten a Aristóteles qué sentía / de la mujer. Pues dice en su escritura, / a lágrimas y llanto en demasía / inclinada bien es de su natura; / envidia y querimonia la seguía, / flojedad y pereza y detractura (...) / Decid, no es de llorar tal desventura, / que rindan las mujeres al perfecto, / al sabio, al necio, al pobre y al que es rico, / al Rey y caballero y pastorcico». Centenera sabía bien de qué hablaba cuando sostenía que ningún hombre podía sustraerse a los encantos femeninos: siendo arcediano de la Catedral de Paraguay, fue juzgado por embriagarse, alardear de aventuras amorosas, y mantener relaciones con una mujer casada. La sentencia, de 14 de agosto de 1590, lo condena "en privación de todo oficio de Inquisición, y doscientos cincuenta pesos de multa» (original en el Archivo de Simancas. Reproducido por Ricardo Palma, Anales de la Inquisición en Lima, Madrid, Ricardo Fe, 1897, tomo I; y por el mismo autor en el suplemento de La Nación, 1 de enero de 1907).

\section{6}

La Recopilación de las Leyes de Indias era un conjunto de más de seis mil leyes ordenadas en nueve libros, de los que el sexto se ocupa en exclusiva de los indígenas. Durante el reinado de Carlos II (1680), una Real Cédula validó esa Recopilación.

27

Ante las reiteradas denuncias de abusos, Felipe II pidió informes al presidente de la Audiencia de Charcas, que transmitió la orden al oidor Francisco de Alfaro. Tras recorrer Tucumán, Cuyo, Buenos Aires y Para- guay, dio las "Ordenanzas de Alfaro» (Asunción, 1612), en las que volvía a prohibir el trabajo forzado de los indígenas, así como su compraventa; reconocía su libertad para elegir patrón: reglamentaba la mita y la formación de pueblos indígenas..

28

Solo algunos ejemplos de cómo las capitulaciones firmadas con diversos conquistadores del Río de la Plata insisten en ello (tomamos las citas de Juan García Santillán, "Legislación sobre Indios en el siglo XV|», Revista de las Españas, Madrid, 1 (1926), pp. 39-43): «la dicha conquista pacificación y población y tratamiento de los dichos indios en sus personas y bienes seas tenido y obligado de guardar» (Capitulación con Pedro de Mendoza, 1534); "prometemos de vos hazer merced de la dicha ysla de Santa Catalina por termino de doze años para en que tengays granjerias y os aprouccheis della con que no podays sacar indios fuera de la dicha ysla» (Capitulación con Alvar Núñez Cabeza de Vaca); «rrepartireis tierras y solares y heredamientos a los pobladores a cada vno según lo que os pareciere ser justo no ocupando ni tomando cosa de los yndios ni de sus sementeras de que actualmente se aprovechan sin su voluntad (...) probeereis que luego se envíen a los dichos pobladores lo necesario para su sustentación y de los yndios y otras personas que con ellos se allegaren (...) que podais hazer en las dichas poblaciones tres yngenios de açucar (...) y que para sustentar los dichos yngenios podais tomar y señalar para cada vno dellos tres cauallerías de tierra sin perjuicio de los yndios (...) con condición que en las dichas poblaciones $y$ pacificaciones y tratamiento de los yndios de aquellas provincias en sus personas y bienes seáis tenido y obligado por todo lo contenido en las hordenanzas e ynstrucciones que para esto tenemos hechas y se hizieren» (Capitulación con Jaime Rasquin); "vos damos licencia y facultad para que podáis dar y repartir cauallerias y tierras en la dicha vuestra governación entre los vezinos españoles que en ella hubiere para que puedan labrar y criar y poblar en ella y tomar vos por vuestra parte sin perjuicio de los yndios ni de otro tercero alguno» (Capitulación con Juan de Sanabria).

La gran figura silenciada: La mujer en el primer siglo de la conquista rioplatense

MAR LANGA PIZARRO 
29

Marilyn Godoy, La conquista amorosa en tiempos de Irala, Asunción, ed. de la autora, 1995.

30

Así lo denomina el arcediano Barco Centenera, en una carta sin fecha y sin firma, escrita desde Perú (donde Centenera se encontraba en 1587) y dirigida a la "Sacra Católica Real Majestad». Se conserva en el Archivo de Indias. La cita, entre otros, Enrique Peña («Apuntes Bio-bibliográficos», edición de La Argentina antes citada), y parece que la recoge Manuel $\mathrm{R}$. Trelles en el tomo IV de la Revista Patriótica del Pasado Argentino.

31

Memorial de 3 de marzo de 1545, Revista de la Biblioteca Nacional de Buenos Aires, tomo I, p. 470. Citado por Efraim Cardozo, Paraguay de la Conquista, Asunción, El Lector, 1989, p. 80

32

Alberto Mario Salas, Crónica florida del mestizaje de las Indias S. XVI, Buenos Aires, Losada, 1960.

33

Las citas procen de Natalicio González, Proceso y formación de la cultura paraguaya, Asunción, Guarania, 1948, p. 102; y Salas, op. cit., p. 20.

La gran figura silenciada: La mujer en el primer siglo de la conquista rioplatense

MAR LANGA PIZARRO los pobladores originarios de América habían desaparecido: las enfermedades importadas, las batallas y el trabajo impuesto explican esa situación.

Resulta ya un tópico afirmar que la conquista rioplatense no se llevó a cabo por medio de las armas sino a través del amor. Aun reconociendo que el concepto de amor ha variado notablemente desde el siglo XVI, no podemos olvidar que el mestizaje se produjo entre unos recién llegados, y unas nativas a las que consideraban inferiores: por ser indígenas y por ser mujeres.

Para el europeo, toda mujer había de someterse al varón. Así lo dispone la Biblia: «las casadas estén sujetas a sus propios maridos, como al Señor; porque el marido es cabeza de la mujer, así como Cristo es cabeza de la iglesia, (...) como la iglesia está sujeta a Cristo, así también las casadas lo estén a sus maridos en todo» (San Pablo, Epístola a los Efesios, 5). Y así lo recomendaba también Fray Luis de León en una de sus obras más influyentes: $L a$ perfecta casada (1583).

A esta idea europea de la superioridad masculina, se añaden las costumbres de algunos grupos indígenas. Como expone Marilyn Godoy,

la mujer araucana era una verdadera esclava del hermano, el padre o el marido que la adquiría en carácter de compra y tenía sobre ella todos los derechos (...) Algunos pueblos conocen el sacrificio humano, femenino en particular; en el Ecuador sacrifican doncellas, en México sacrifican esclavas al Dios del Agua y al Dios del Fuego y está muy generalizada la idea de que al rey se le debe enterrar con algunas de sus mujeres ${ }^{29}$.

Según Schmidl, en el Río de la Plata, «el padre vende su hija, lo mismo el marido a su mujer cuando no le gusta, y el hermano a la hermana; una mujer cuesta una camisa, un cuchillo, una hachuela, u otro rescate». También era habitual regalarlas para establecer pactos, y la mujer indígena pronto entendió que, si mezclaba su sangre con la de un español, su descendencia gozaría de privilegios.

El panorama que resulta de estos hechos no es precisamente el del «amor» en ese lugar de América cuya floreciente poligamia le hizo merecer el sobrenombre de «Parayso de Mahoma» ${ }^{30}$. El 3 de marzo de 1545, el capellán Francisco González Paniagua escribía escandalizado en su Memorial al Rey: «Mahoma y su Alcorán no permitían más de siete mujeres, $\mathrm{y}$ acá tienen algunos setenta» ${ }^{31}$.
Como apunta Alberto Salas, «la sexualidad indígena ejerció un atractivo fuerte y completo en la psiquis europea, abriéndole la imagen de una actividad sexual libre, natural y sin controles (...) las mujeres de América fueron parte del botín debido a los conquistadores» ${ }^{32}$.

A pesar de su importancia en la consolidación de la nueva sociedad, las veces en que las indígenas aparecen en las crónicas coloniales suelen carecer hasta de nombre. Ignoramos incluso el de las que tuvieron especial trascendencia en el devenir de la historia.

\subsection{La amante de Salazar (1539), la cómpli- ce de los españoles}

Desconocemos quién era la mujer que advirtió a Salazar de que los indígenas planeaban un ataque, aprovechando una procesión de 1539. El éxito estaba casi asegurado: los españoles carecerían de armas con las que defenderse, y el número de los atacantes era mucho mayor. Sin embargo, gracias al aviso de una indígena, los conquistadores acabaron con los líderes de la conjura. Díaz de Guzmán y Félix de Azara hablan de ella como «una criada india» de Salazar. Otros escritores la convierten en su amante y, como le sucedió a la famosa Malinche, la tildan de traidora: así lo hacen Natalicio González («para salvar la vida de su amante, la mujer traicionó a los de su raza») y Alberto Salas («el amor que nos parece indudable en las indias, acabó haciéndolas traidoras») ${ }^{33}$.

Al tema de la amante de Salazar dedica Hugo Rodríguez Alcalá dos de sus Romances de la Conquista. El primero sigue a los cronistas en el relato de los hechos. En el segundo, Salazar tiene un sueño, y la indígena le ayuda a interpretarlo, desvelándole así los proyectos de su pueblo:

Soñé con bosques de flechas / mojadas en roja sangre...

-Era sangre de cristianos / la sangre que tú soñaste.

-Volaba un bosque de flechas / haciendo noche en el aire.

-Flechas que tú viste en sueños / eran flechas de mi padre.

-En mis sueños las serpientes / pululaban a millares. -Las serpientes de tus sueños / eran indios desleales. -Murciélagos en mi sueño / presagiaban negros males.

-Guerrero de piel de luna, / ciñe tu yelmo brillante, / arma tu brazo de hierro / antes que sea muy tarde / y antes que vuelen las flechas / pártelas en dos mitades. 
La recreación de Helio Vera en su cuento «Primeras letras» ${ }^{34}$ resulta altamente sugerente. Frente a la actitud tradicional, no se enjuicia a la mujer ni como traidora a su pueblo, ni como salvadora de la conquista. La indígena observa con admiración un libro: «La india Juliana hojea, absorta, el libro que el capitán Juan de Salazar de Espinoza le ha dejado sobre la mesa. Sus ojos se llenan con el deslumbrante color de los grabados (...) ni hubiera pensado que existían sobre la tierra objetos tan extraños y bellos». Desde la fascinación por los dibujos, llega el ansia de leer, una idea que satisface tanto a su amante como a Centenera, convencido de que el acceso al castellano y a la lectura es el medio para difundir su doctrina. Tras esa escena, se produce un corte: nos encontramos ante la maquinación de los indígenas para acabar con las injusticias de los españoles. En contra de todo pronóstico, estos últimos aparecen armados: "Los indios, sorprendidos, no atinan a reaccionar. Están convencidos de que los enemigos conocieron el plan mediante la magia». Sin embargo, poco ha tenido que ver la magia en la victoria:

El capitán retorna a su chacra, cansado, sucio y sudoroso, la coraza moteada de manchas de sangre. Lo recibe una Juliana ávida de seguir penetrando en el universo excitante que se despliega en los textos y en los grabados. Esta noche, Salazar deberá olvidar la fatiga de la matanza y leerle (...) le debe la vida a esta mujer que se apretuja contra su pecho y que ahora le invita a acariciarla (...). Lo que ella le contó hace dos noches permitió detener el artero golpe de mano del Jueves Santo.

En el relato, Juliana ha dado cuenta de la sublevación para poder continuar adentrándose en el mundo de las letras. La Juliana de Helio Vera rompe con la oralidad de las culturas indígenas: la escritura es un bien tan preciado que hace todo lo necesario para que nadie interrumpa su proceso de adquisición. Por ello, este personaje se puede considerar un emblema del cambio cultural que supuso para estas mujeres el contacto con los españoles.

A pesar de la importancia de las nativas en la configuración de la sociedad colonial, apenas hay literatura sobre ellas: su presencia se suele limitar a la de personajes secundarios en obras que otros protagonizan. Constituye una excepción Liropeya, cuyos avatares sirven de contrapunto a los de Lucía Miranda.

\subsection{Liropeya (hacia 1570): la rebelión me- diante el suicidio}

La historia de Liropeya anticipa la visión del indio que se difundirá en el Romanticismo y, aunque no se la califique como tal, tiene aspecto de leyenda inserta en la crónica de Centenera: la indígena ha puesto como requisito para la boda que su amado venza a cinco caciques. Cuando le falta uno, aparece un español, que se enamora súbitamente de Liropeya. Ella pide a su prometido que no mate al soldado, los tres mantienen una conversación en la que los indígenas demuestran la grandeza de su amor, y el español se va. Sin embargo, poseído por su pasión, decide matar a Yandubayo para apoderarse de la muchacha. Mientras el soldado lo entierra, como le ha pedido Liropeya, ella se suicida.

Resulta lógico que la historia atrajera a los románticos rioplatenses, fundamentalmente a los uruguayos, ya que, al crearse el nuevo estado (1830), se proyectó aniquilar a los charrúas, para dar seguridad a los estancieros, que se quejaban de los robos de ganado ${ }^{35}$. Este pueblo arrastraba una pésima fama desde los textos coloniales, y los propios españoles habían intentado acabar con él sin éxito ${ }^{36}$. Aunque el Uruguay independiente barajó la posibilidad de llevar a los charrúas a la Patagonia o forzarlos a trasladarse hacia Brasil, se optó por la aniquilación: el primer presidente, Fructuoso Rivera, les aseguró su amistad, y los convocó a una reunión en el Queguay en abril de 1831. Allí les quitaron las armas y los caballos. El presidente disparó al cacique, y el ejército emprendió la matanza. Después, se trasladaron al campamento para asesinar a las mujeres y a los niños, y repartieron a los supervivientes como esclavos.

Sobre el caso de Liropeya, Adolfo Berro escribió el poema «Yandubayú», que se publicó póstumamente en el volumen Poesías (Montevideo, Imprenta Nacional, 1842). Los versos octosílabos comienzan la historia in media res, y la acaban con el suicidio de la indígena: «Abre otra fosa, le dice / ¡oh maldecido cristiano / y con la espada sangrienta / se pasa el seno angustiado». Además, el compositor uruguayo León Ribeiro creó la ópera Liropeya (1881), que sería estrenada en el Teatro Solís; y el escritor argentino-uruguayo Florencio Escardo puso la historia en boca del personaje femenino de Abayubá (Montevideo, Imprenta La Tribuna, 1873): Tupaayqué cuenta que «Lirompeya» fue violada por el conquistador «Caraballo», y el protagonista le responde:
34 Publicado en Caravelle, 70 (1998), pp. 299-305, e incluido en V.AA. Cuentos del Mercosur, Santiago de Chile, Ril, 2002.

35

También Argentina, en su afán de consolidar un proyecto civilizador urbano y blanco, chocó con el problema de los «indios salvajes», que saqueaban, robaban y destruían las estancias. Para atajarlos, hubo dos "campañas del desierto»: la de Juan Manuel de Rosas (1833-1834) y la de Julio A. Roca (1878-1880) Susana Rotker ("Cautivas argentinas: a la conquista de una nación blanca», Working Papers of the Latin American Program, 233, 1997) da los siguientes datos: «entre 1822 y 1830,538 individuos ocuparon $7,800,000$ hectáreas en la pampa (...) los Anchorenas -primos de Juan Manuel de Rosas (...)-, acumularon 352,000 hectáreas y su hermano Prudencio, 73 mil. La Conquista del Desierto comandada por Roca en 1878 y 1879 agregó unas 54 millones de hectáreas al 'patrimonio nacional'. Esos bienes fueron entregados en gran parte a especuladores y terratenientes».

36

Como señala Azúa en su obra citada, los españoles lucharon contra ellos varias veces. En la «batalla del Yì (1702), acompañados por dos mil guaraníes, mataron a varios centenares de charrúas y condujeron a medio millar a pueblos de las misiones. Además, en 1751, el Gobernador de Montevideo, José Joaquín de Viana, dio orden de "sujetar a los charrúas a la cruz y a la campana o pasarlos a cuchillos a todos los varones mayores de doce años». La mala fama puede ejemplificarse por la larga descripción de Félix de Azara, que empieza recordando que «mataron a Juan Díaz de Solís» y, después de dar otros datos, se centra en la falta de higiene: «tienen muchos piojos, (...) no lavan nunca sus vestidos ni sus manos, ni su cara, ni su cuerpo (...) no se puede encontrar nada más sucio ni, por consecuencia oler nada más apestoso. Tampoco barren jamás sus habitaciones, y no cosen ni hilan (...) han dado más que trabajar a los españoles y les han hecho derramar más sangre que los ejércitos de los incas y de Moctezuma».

La gran figura silenciada: La mujer en el primer siglo de la conquista rioplatense

MAR LANGA PIZARRO 


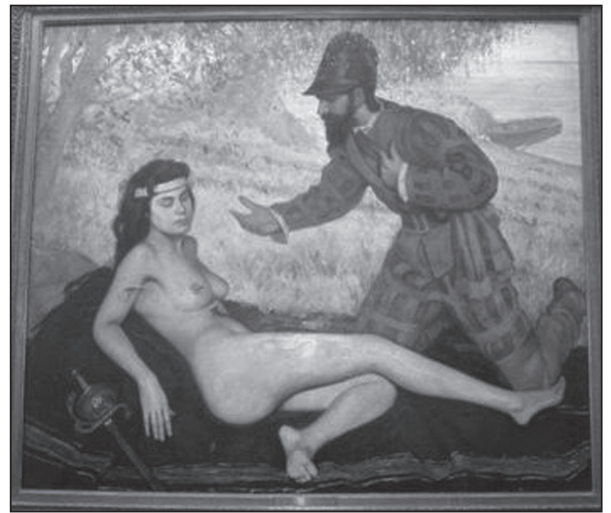

Liropeya. Cuadro en la Asociación Correntina General San Martín.
37

Javier García Méndez, "Azul..., Tabaré, El zarco: Líneas divergentes de un fin de siglo", Argos (México), 18 (2001). Sin embargo, cabe recordar que, aunque Zorrilla estaba imbuido por un espíritu romántico que le hizo caer en los tópicos del momento, cantó a los charrúas con sinceridad. «El ángel de los charrúas» (1877) acaba así: "se apagó la luz del mundo, / se ahogó la dulce armonía, / volvió la sombra a envolver / los muertos en la campiña /. (...) ¡Cayó una raza inocente! / ¡Sin dar un paso hacia atrás / dobló la bronceada frente! / ¡Cayó una raza inocente / para no alzarse jamás!» (Rimas y leyendas, Montevideo, Arca, 1968).

\section{8}

"Carta de Alonso Riquelme de Guzmán a su padre Ruy Díaz de Guzmán», Colección García Viñas. La recoge Ricardo de Lafuente Machaín, Capitanes de acero, Buenos Aires, 1942, p. 81.

39

A finales del periodo que nos ocupa, había en el Río de la Plata unos doce mil españoles y descendientes de estos, y un millón de indígenas.

40

Reproducido por Óscar Teran, Alberdi póstumo, Buenos Aires, Puntosur, 1988, p. 150.

41

José Torre Revelló, Documentos históricos y geográficos relativos a la conquista y colonización rioplatense, 1941, I, 21. Citado por María Teresa Condés Palacios, op. cit., p. 364.

La gran figura silenciada: La mujer en el primer siglo de la conquista rioplatense

MAR LANGA PIZARRO conozco esa historia; hé aquí lo que nos trae el estrangero, sangre, ruina, desgracia. Oh! malditas virtudes las que nos quiere enseñar asolando nuestro país, talando nuestros campos, robando nuestras mujeres, asesinándonos desde lejos con sus armas de explosion (p. 6).

Juan Zorrilla de San Martín se hizo famoso por el poema épico católico Tabaré (1888), del que Javier García Méndez sostiene que "contribuye a borrar de la historia esa atrocidad, componiendo una

sírvennos como esclavos y nos dan sus hijas para que nos sirvan en casa y en el campo, de las cuales y de nosotros hay más de cuatrocientos mestizos entre varones y hembras; porque vea vuestra merced si somos buenos pobladores, lo que no conquistadores ${ }^{38}$.

Cuando murió el gobernador Domingo Martínez de Irala (1556), su testamento operó una suerte de legalización del mestizaje: especificaba que había tenido tres hijos y seis hijas con siete indígenas (seis criadas suyas, y una de Diego de Villalpando). Unos años antes, había casado a algunas de esas hijas, a las que daba el tratamiento de Doña, con españoles partidarios de Alvar Núñez Cabeza de Vaca, como medio para terminar con la división que había surgido entre los españoles. Las bodas sirvieron, de hecho, para empezar a considerar españoles a los descendientes de estos, aunque uno de sus progenitores no fuera europeo. De ese modo, se creó una brecha entre las criollas y mestizas y las indígenas ${ }^{39}$ : estas últimas quedaron relegadas a un papel casi exclusivo de sirvientas y concubinas.

El aumento del número de mestizos pronto provocó el recelo de los españoles. En 1579, el tesorero Hernando de Montalvo escribía al rey:

Estas provincias han menester gente española, sobre todo porque es muy poca y van cada día en más crecimiento los hijos de la tierra, ansí criollos como mestizos, que de cinco partes de la gente, las cuatro son de ellos, (...) tienen muy poco respeto a la justicia, hacen cada día muchas cosas dignas de castigo y no se castiga ninguna, (...) son muy curiosos en las armas, grandes arcabuceros y diestros a pié y a caballo ${ }^{40}$.

\subsection{Juana Ortiz de Zárate, la Gobernadora (1576-1584)} cuántos años?». La ventaja del literato es que puede hacer valer su imaginación para dotarla de una imagen: "sus abundantes cabellos. / Y éstos, sobre sus hombros / y las curvas de sus pechos, / aire de diosa le daban / con centelleos de ébano». De ese modo, la literatura suple las omisiones de la historia.

\section{LAS MESTIZAS}

El mestizaje comenzó en el Río de la Plata desde la llegada de los primeros españoles, que quedaron fascinados por la libertad sexual y la poligamia que se practicaban en América. Se regocija de ello con ironía Alonso Riquelme de Guzmán, en una carta que dirige a su padre, desde Asunción, en 1545:
De la relación entre el adelantado Juan Ortiz Zárate y doña Leonor Yupanqui, emparentada con el inca Atahualpa, nació Juana, que fue reconocida como hidalga por una Real Cédula de 1570. Mediante una carta del 23 de agosto de 1587, Hernando de Montalvo daba cuenta del fallecimiento del adelantado, y de su voluntad de dejar como sucesora de la gobernación a Juana: «murio EladeLant.Joan/ortiz de Çarate a.26. de Enero del año de76. dexo una hija natural avida en una yndia a La cual dexo por su unica Eredera de toda su hacienda y por governadora delas provincias que fue por La segunda vida de que. V. mg.»41.

Juan Ortiz de Zárate nombró a Garay Teniente Gobernador del Río de la Plata en 
1574, y le encargó que se ocupase del cumplimiento de las cláusulas de su testamento. Al morir Zárate, Garay fue a Charcas, donde intervino en la boda de Juana con el sevillano Juan Torres de Vera y Aragón, oidor de Chile y de Charcas. El virrey de Perú, Francisco de Toledo, quería que ella se casara con su hijo, y los mismos planes tenía para el suyo el oidor Juan de Matienzo: cada uno pretendían convertir a su vástago en el nuevo adelantado. Frustrados sus planes, el virrey mandó encarcelar a Torres y a Garay. Para entonces, este último había precipitado su marcha a Asunción, llevando el nombramiento que Torres le había otorgado, y que lo convertía en Lugarteniente General del Río de la Plata.

A esta historia dedica Julio A. Sierra $\mathrm{La}$ Nusta Ortiz: vida y amores de una princesa inca, donde mezcla múltiples personajes reales con algunos inventados, como el mestizo Alonso, que tiene gran relieve en una novela que une los recursos de la ficción (cambios súbitos de escenario, flash-back, invención de anécdotas...) con la inclusión de las diversas versiones que se han dado para los mismos hechos, e incluso con fragmentos de documentos reales ${ }^{42}$. Las feroces luchas políticas del momento, las dificultades en los preparativos para la expedición de Zárate, los avatares del desgraciado viaje, y los últimos derroteros de los incas hasta la muerte de Tupan Amarc, comparten espacio con la biografía de Juana.

El relato comienza narrando la llegada de Zárate a Lima, y su unión con Leonor Yupanqui. Juana se cría en la confluencia de dos culturas, por eso se erige en defensora de los indígenas (por ejemplo, logra salvar de la castración a un pastor al que habían sorprendido en un acto de zoofilia, p. 82), pero jamás se plantea si la conquista es lícita o si los españoles tienen derecho a someter a los nativos.

En la novela, podemos observar la posición de las mujeres en la sociedad de esa época. Los intentos de evitar que puedan heredar aparecen varias veces: «mujeres adelantadas y encomenderas son siempre un problema» ( $\mathrm{p}$. 61), sostiene uno de los personajes, con idénticos argumentos a los que Toledo expondrá más adelante: «todavía no sé cómo Su Majestad permite que huérfanas y viudas sigan heredado. Es un peligro para la estabilidad de este reino» (p. 181). Y el mismo Toledo, que como virrey trata de aprovecharse de su deber de proteger a viudas y huérfanas, afirma con desprecio: «Bah, ninguna mujer es libre de elegir nada» (p. 203).

La vida de Juana Ortiz de Zárate interesó también a Pedro Tadeo Acevedo, quien publicó el estudio Amores de la princesa Ynca Leonor Yupanqui y el romance de la indobispana Juana Ortiz de Zárate (Buenos Aires, Imprenta de la Universidad, 1935); a José Ignacio Garmendia, autor de El casamiento de Doña Juana Ortiz de Zárate: crónica histórica colosal (Buenos Aires, Jacobo Peuser, 1966), y a Hugo Rodríguez Alcalá, que la usa como base para uno de sus Romances de la Conquista.

\subsection{Ana Díaz, la pobladora (1580)}

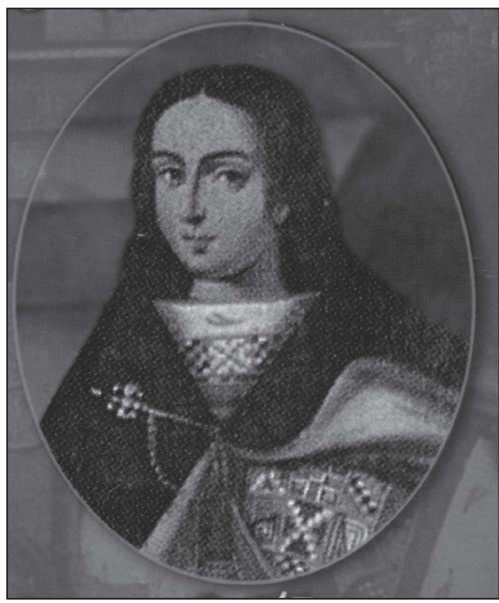

Juana Ortiz de Zárate. Detalle de la portada de Julio A. Sierra, La ñusta Ortiz.

A finales del siglo XVI, la vida no era fácil para los asuncenos: las invasiones desde Brasil hacían peligrar los asentamientos limítrofes. La esperanza de la región pasaba por buscar una salida al mar. Por ello, cuando Juan de Garay asumió el gobierno de Asunción, decidió repoblar Buenos Aires (1580), que había sido despoblada por orden de Irala (1541). Según la carta que envió Garay el 20 de abril de 1582, la refundación se llevó a cabo con 74 pobladores, de los que 53 eran criollos y mestizos. Entre ellos se encontraba Ana Díaz, considerada como la única mujer de la expedición. Sin embargo, esto no es cierto: era la única que no viajaba con un familiar varón, pero los documentos recogen los nombres de casi una treintena de mujeres, esposas e hijas de los pobladores. Y ello sin contar a las indígenas, cuyo número se desconoce.

No existen muchos datos sobre Ana Díaz: parece que era viuda, que en Asunción trabajaba la tierra, que instaló una pulpería en su solar de Buenos Aires, y se casó allí con el mestizo Juan Martín. Su figura ha quedado en el recuerdo de distintos literatos. El poeta paraguayo bilingüe (en castellano y guaraní) Carlos Agustín Bedoya (1938), conocido como Tumbita, es autor de un poema musicalizado «Mamá Ana Díaz». Además, la historiadora Josefina Cruz de Caprile le dedica un capítulo de la novela Juan de Garay, el conquistador conquistado (Buenos Aires, Instituto de Cultura Hispánica, 1973); Hugo Rodríguez Alcalá, uno de sus Romances de la Conquista; y Roa Bastos la menciona en un episodio de Yo, el Supremo (Buenos Aires, Siglo XXI, 1974), en el que juega con la poca precisión del plano de Garay, y con la escasa fiabilidad de los testimonios. No es difícil que el autor paraguayo recordara el cuento «La
42

Como el Bando de Zárate de 1575 (p. 125), la Real Cédula de 1570 que reconocía a Juana Ortiz y le concedía los títulos y haciendas de su padre (p. 179), el Acta de la segunda fundación de Buenos Aires (p. 248)...
La gran figura silenciada: La mujer en el primer siglo de la conquista rioplatense

MAR LANGA PIZARRO 
43

Simón Bolívar, "Discurso», Correo del Orinoco, 19-22, del 20 de febrero al 13 de marzo de 1819 .

44

Citado por John M. Lipski, Un remanente afrohispánico: el habla afroparaguaya de Camba Cua, digitalizado en http://www.personal.psu.edu/jml34/afropar. pdf. Otros autores, como José María Iraburu, aumentan la cifra hasta quince millones

45

Archivo de Indias, tomo 28 , documento 825, fechado en $\mathrm{Va}$ lladolid el 19 de julio 1534. Lo cita con sorpresa Norma Videla Tello, "La Argentina, un país de blancos. El ocultamiento de la mestización», 2000, digitalizado en http://www.magicasruinas.com.ar/revdesto0 48 .htm

46

Durante la primera etapa de la conquista (1493-1595), el envío de esclavos a América estuvo prohibido, con la salvedad de las licencias que el rey concedía a través de contratos puntuales. Más tarde (1595-1778), se difundió el sistema del asiento: un contrato de arrendamiento de barcos armados, por un tiempo determinado o para una acción concreta. La necesidad de mano de obra llevó al establecimiento del Reglamento de Libre Comercio en 1778 .

47

Tribunales leg 94 Expediente 15 Sala IX 36-7-3. Se halla en A.G.N. Proyecto UNESCO Digitalización de documentos sobre esclavos (http://www.mininterior.gov.ar/larutadelesclavo/interiorcd.htm).

\section{8}

Juan Francisco Maura, Españolas de ultramar en la historia $y$ en la literatura (siglos XV a XVII), Publicaciones de la Universidad de Valencia, 2005, p. 115.

49

La venta de vino se prohibe a los negros en un bando fechado en Buenos Aires el 17-8 1620 (Cabildo de Buenos Aires. Actas. Tomo 3 Sala 9 27-6-7 foja: 342). Además, contra la prohibición del trabajo de los negros en las pulperías protestaron sus dueños, según recoge el documento fechado en Buenos Aires el 17-2-1642 (ibid. Tomo 6 Sala 9 27-7-2 folio: 90-90vta). Estos documentos, y muchísimos

La gran figura silenciada: La mujer en el primer siglo de la conquista rioplatense

MAR LANGA PIZARRO fundadora», donde Manuel Mujica Láinez (op. cit.) imaginó a Ana Díaz acosada por todos los varones de la nueva Buenos Aires.

\section{LAS NEGRAS Y LAS MULATAS}

La presencia de negros en la América conquistada por españoles es un tema que muchas veces se ha obviado, negado o minimizado. Así hablaba Bolívar en su famoso discurso de Angostura (1819): «no somos europeos, no somos indios, sino una especie media entre los aborígenes y los españoles. Americanos por nacimiento y europeos por derechos» ${ }^{43}$. Evidentemente, hay en esta cita una reivindicación de lo español y lo indígena, y una ocultación de la presencia negra. Sin embargo, el historiador chileno Rolando Mellafe estima que, durante el periodo colonial, llegaron a Indias unos tres millones de esclavos negros ${ }^{44}$.

Por lo que respecta al Río de la Plata, la documentación existente certifica que ya los integrantes de la expedición de Mendoza solicitaron llevar consigo un gran número de esclavos negros de ambos sexos ${ }^{45}$. Poco después, tuvo lugar en Buenos Aires el primer remate público: tras su naufragio (1538), Pancaldo fue sometido a juicio por no haber pagado aranceles para transportar dos esclavos, que fueron subastados el 20 de enero de 1539.

El primer asiento real ${ }^{46}$ se ajustó con Pedro Gómez Reynel (Real Cédula del 30 de enero de 1595), a quien se concedió, por término de nueve años, el derecho de llevar anualmente a Indias 4.250 negros esclavos, de los que seiscientos estaban destinados al Río de la Plata.

otros, pueden consultarse en A.G.N. Proyecto UNESCO, antes citado.

\section{0}

Sirvan de ejemplo: "Bando que ordena abandonar los trabajos en las obras públicas en la ciudad, y que vagabundos, negros y mulatos se presenten a trabajar en la cosecha» (1312-1766, Buenos Aires: Bandos libro 3 foja: 109-109vta Sala 9 8-10-3); «El procurador General peticiona al Cabildo para que los negros y negras sean obligados a vivir conforme a las leyes en vigencia» 15-5-1736, Buenos Aires: Cabildo de Buenos Aires. Actas. Tomo 24 Sala 9 27-8-7 fojas: 101 va y 103), "Bando que ordena a los indios, negros y mulatos sin ocupación en la ciudad que se coloquen en el término de 15 días》 (6-121745, Buenos Aires: Bandos libro 1 folio 80 Sala 9 8-101, 1743-1753); "Bando que prohíbe a los negros y mulatos el juego y los bailes indecentes» (3-11-1766, Buenos Aires: Bandos libro 3 foja: 101 reverso y 102 anverso Sala 9 8-10-3), «Bando prohibiendo los bailes indecentes de negros y mulatos en la ciudad» (6-51766, Buenos Aires: Bandos libro 3 foja: 77-82 Sala 9 8-10-3), etc.

51

Norberto Ras, "Criollismo y Modernidad: Un análisis formal de la idiosincrasia criolla». Digitalizado en http:// www.anav.org.ar/sites_personales/12/index.htm
Reclutados en los territorios de las actuales Angola, la República Democrática del Congo y Guinea, los esclavos eran vendidos en mercados como el del puerto angoleño de San Pedro de Loanda. Los barcos negreros se dirigían a destinos americanos como Buenos Aires, desde donde los esclavos se distribuían al interior de la provincia. El índice de mortandad durante el viaje era elevadísimo: por ejemplo, un documento fechado en Montevideo en 1804 da cuenta de la llegada «de la Fragata portuguesa El Joaquín con esclavatura procedente de Mozambique, iniciando su viaje con 301 negros, de los cuales sobrevivieron 30 por las enfermedades» ${ }^{47}$. Desde que el adelantado Alvar Núñez Cabeza de Vaca «hace publicar un pregón para que los oficiales reales hiciesen fabricar un hierro para marcar a los esclavos traídos de España» ${ }^{48}$, hasta la prohibición de la práctica (1784), una vez en tierra, los esclavos eran medidos y nuevamente marcados con hierro.

Generalmente, los negros desarrollaban labores agrícolas, tareas domésticas y los oficios artesanales que los españoles no querían realizar. En los momentos más conflictivos, también los alistaron para combatir. Sin embargo, se les prohibieron actividades como la venta de vino ${ }^{49}$, seguramente debido a la mala fama que arrastraban: no faltan los documentos en los que se hacen llamamientos a «vagabundos, negros y mulatos» como si de una sola categoría se tratara, ni los que les dan plazo para colocarse, los instan a vivir conforme a las leyes, o les prohíben el juego, los cantos y los bailes «indecentes» ${ }^{50}$.

Por lo que respecta a las negras, cabe recordar que los esclavos estaban obligados a viajar con sus esposas; y que, en algunas capitulaciones, se especifica la proporción de esclavas que se han de transportar: generalmente, un tercio del total. Estas mujeres trabajaron fundamentalmente en el servicio doméstico y como amas de cría. Por otra parte, según señala Coria en la obra antes citada, la negras «fueron siempre consideradas como el botín obligado o el premio cotidiano de los hombres blancos, llevados muchas veces por la leyenda de la insaciable capacidad sexual». $\mathrm{Al}$ contrario de lo que sucedió en el caso de las indígenas, los hijos de las negras y los blancos no fueron reconocidos por estos, sino que ingresaron el cómputo de los esclavos.

Norberto Ras estima que, en el virreinato del Río de la Plata, la población negra superó el $20 \%{ }^{51}$. Otros autores aumentan la cifra hasta el doble. Sea como fuere, en el siglo XIX 
se produce una «misteriosa desaparición» de negros rioplatenses: como destacó Susana Rotker en la obra antes citada, "a comienzos del siglo XIX una de cada tres personas de Buenos Aires era negra ${ }^{52}$, mientras que a fines de la década de 1880 la proporción se redujo a menos del dos por ciento». Similares son los datos para Paraguay y Uruguay. La disminución se ha tratado de explicar por las mezclas de sangre, las enfermedades y la participación en las guerras. Pero, al margen de esos motivos, hay uno ideológico: la negación de esa ascendencia, por el afán de imitar los modelos sociales europeos o por simple racismo. Este último elemento está ya presente los textos coloniales: cuenta Centenera en su octavo canto que, en la isla de Santiago, "A mi posada vino un caballero / de buena compostura y bien tratado, / alegre, conversable y placentero, / y con una encomienda señalado. / Tiene una negra allí mucho dinero, / con ella se casó el desventurado. / ¡Mirad pues el dinero a cuánto obliga!».

Si hacemos un somero y nada exhaustivo repaso a la literatura negra rioplatense, tenemos que partir de Joaquín Lenzina («Ansina», 1760-1860), el payador al que Artigas compró para otorgarle la libertad. A su voz se unieron otros payadores, reales (Higinio Cazón, Luis García, Gabino Ezeiza...) o literarios (como el "payador moreno» del libro V de Martín Fierro). Además, hay múltiples referencias a los negros en los tangos decimonónicos ${ }^{53} ; \mathrm{y}$, en el siglo XX, un buen número de negros se incorporó a la creación literaria.

La literatura rioplatense que se centra en los negros suele recoger hechos posteriores a la Independencia ${ }^{54}$, como la celebración de las leyes de libertad de vientres ${ }^{55}$ o las quejas por la discriminación ${ }^{56}$. Entre las excepciones, se halla Canto al África (1877), de Casildo Gervasio Thomson, donde se denuncia la crueldad de la trata de esclavos. El poema comienza con una visión idílica del continente africano y, en una interesante inversón del tópico de civilización y barbarie, es el blanco el que aparece como una bestia que termina con la armonía mediante la esclavitud. También el poema de Carlos Carbone «Que toquen sus tambores» trata el tema de la esclavitud, esta vez centrándose en la experiencia de un barco negrero ${ }^{57}$.

Por lo que se refiere a las negras y mulatas, su presencia literaria, escasa y casi siempre secundaria, suele reforzar el tópico de la sensualidad. En el siglo XVII, el español Juan del Valle y Caviedes las describía así en «Caballe-

ros chanflones» ${ }^{58}$ : «Manda que toda mulata / la del turbante mejor / que al cielo sube el copete / para ser presa del sol, / dé los cariños a cuarto; / porque una pobre afición / les pide una ceña vuelta / en un medio real de amor». Dos centu-

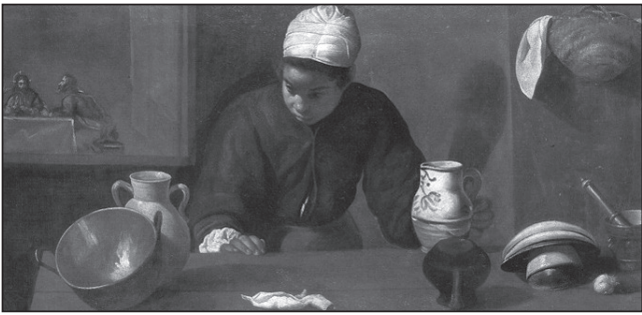

Diego Velázquez, La mulata (ca 1617).

rias después, la visión del

nicaragüense Rubén Darío, en «La negra Dominga» ${ }^{59}$, no había variado sustancialmente: «Serpentina, fogosa y violenta, / con caricias de miel y pimienta / vibra y muestra su loca pasión: / fuegos tiene que Venus alaba / y envidiara la reina de Saba / para el lecho del rey Salomón». En las milongas rioplatenses del siglo XX, las negras continúan caracterizadas por su belleza (por ejemplo, la letra de «Azabache», escrita en 1942 por Homero Expósito, dice: «^Ay morenita, tus ojos / son como luz de azabache! / Tu cala parece un sueño / ¡Un sueño de chocolate!»), y solo se tratan sus problemas de forma tangencial (como ocurren la famosa «Negra Maria», de Homero Manzi, 1942). Recientemente, en Mulata del diablo (México, Fontamara, 1998), de Juan Trigos, la mulata seguía siendo un dechado de belleza y erotismo que, a cambio de mantener relaciones sexuales con el diablo, conseguía la eterna juventud. Así pues, el paso de los siglos no ha servido para que la literatura profundice en la problemática de la mujer negra, sino para que se reincida en los tópicos acuñados.

\section{CONCLUSIÓN}

Como hemos podido ver, las mujeres tuvieron un papel fundamental en los cambios se operaron en el Río de la Plata durante el primer siglo de presencia española. Los conquistadores llegaron acompañados por mujeres blancas de toda condición: esposas, criadas, esclavas, solteras que buscaban un mejor porvenir... Los españoles no se privaron de poblar la zona mezclando su sangre con la de las indígenas, a las que despreciaron a pesar de sus atractivos sexuales; se casaron con las mestizas, a quienes dieron rango de es-

52

Señala John M. Lipski (Un remanente afrohispánico..., op. cit.): «En 1843, cuando la trata africana al Plata ya había cesado, unos 4,300 negros vivían en Montevideo, cuya población total era de 31.000 .
En (...) el censo de 1777, los negros representaban un $30 \%$ de la población de Buenos Aires (Comadrán Ruíz 1969). El censo de 1810, en vísperas de la independencia, también registraba un $30 \%$ de pobladores negros y mulatos».
53

Existen numerosos estudios que establecen la relación del tango (y también del flamenco) con la música africana.

54

Por ejemplo, Guido Rodríguez Alcalá es autor de «El negrito Pilar» (Curuzú cadete, Asunción, Criterio, 1990), que trata sobre un negro esclavo de Gaspar Rodríguez de Francia, que se convierte en parte del aparato represivo del estado.

55

John Lipski (A History of AfroHispanic Language. Five centuries, five continents, Cambridge University Press, 2005. Apéndices en http://www.personal.psu. edu/faculty/i/m/jml34/afrotext. doc) recoge, entre otros muchos ejemplos, la anónima "Carta a la negra Catalina a Pancho Lugares», de 1830 («tio Juan, mi malido, quieli también esclibí. El es neglo bosalona pelo neglo fedelá y agladecido a la Patlia que le dió la libeltá») y el "Canto patriótico de los negros celebrando la ley de libertad de vientres y a la constitución", de Francisco Acuña de Figueroa (1944).

56

Entre ellos, el famosísimo "Romance de la niña negra», del argentino Luis Cané (1897-1957).

57

Los dos textos citados los recoge Alejandro Solomianski en Identidades secretas: la negritud argentina, Rosario, Viterbo, 2003.

58

Recogido por Monica Mansour, La Poesía Negrista, México, Era, 1973, p. 70.

59

Apareció en 1892, en la publicacón periódica cubana La Caricatura. Lo recoge Enrique Noble (ed.), Literatura afrohispano-americana. Poesía y prosa de ficción, Massachusetts, Xerox, 1973, p. 90.

La gran figura silenciada: La mujer en el primer siglo de la conquista rioplatense

MAR LANGA PIZARRO 
60

Julio Cortázar, Rayuela, Buenos Aires, Sudamericana, 1963, p.

20. pañolas; y procrearon con las negras, aunque las discriminaran abiertamente.

A pesar de ello, las referencias a las mujeres del primer siglo de la conquista rioplatense son escasas, tanto en las crónicas coloniales como en las recreaciones literarias posteriores. Además, no por previsible nos parece menos sorprendente que, conforme «la otra» es «más otra», mayor resulte su invisibilidad. Parece que, a los conquistadores (a los de las crónicas y a los de la literatura), se les puede aplicar la frase de Cortázar, que hablaba de tiempos y personajes muy diferentes de los que aquí nos ocupan: el colmo de soledad conducía al colmo de gregarismo, a la gran ilusión de la compañía ajena, al hombre solo en la sala de los espejos y los ecos (...) entraban en la peor paradoja, la de estar quizá al borde de la otredad y no poder franquearlo. La verdadera otredad hecha de delicados contactos ${ }^{60}$.

Un paraíso de Mahoma no existe sin mujeres. Ninguna realidad actual puede entenderse sin tener en cuenta el pasado. Por ello, es necesario desterrar tópicos: franquear el borde de la otredad para descubrirla. 